\title{
On the Notion of Special in Crafting
}

\author{
W.B. Cane \\ University of Victoria
}

I have nurtured, persevered with, labored over, a dream for six years now. The dream is $60 \%$ complete and at this rate will transform fully into a special object some four years from now. To be brief, the object is a hot rod. Among the myriad things that this car has taught me is an appreciation of the notion of special craftsmanship. The notion of special in this context is not the same as "feeling special" though I have felt many times both negatively and positively special as a result of my endeavors. Nor is it the ego special of an adolescent though the object which has been my vehicle, for appreciation of special may be seen as a vestige of adolescence. Neither is this crafting special in a personal sense, for others have shared in the development of the ideas, the perfecting of components, the discussion of concepts, and have shared in the creative process. Some have not shared in the meaning of special and are now spectators. These are the people who do not understand the meaning of special-ness in the process of crafting something.

The notion of special for me comes then from the crafting of a car from temporal picture to functioning automobile. The notion includes that the special object is a teacher both to oneself and to others. The notion is a cause for defense and celebration. Special here includes the sensuality of line and motion and the unnerving notion that we are, after all, connected through the crafting endeavor with our ancestors. It includes an appreciation of animate motion created from the inanimate. The specialness of crafting something special has scared me by allowing me a glimpse at the infinite possibilities of man's creative genius. My appreciation of the notion of special has developed over years of commitment to a car.

\section{Work}

There are the more obvious rewards derived from building a carrewards such as accolades and praise. I shall not focus on these but rather on the more personal and secret rewards that an observer, perhaps even a close one, would not recognize. It is these secret rewards that lie at the heart of the notion of special. They bring me to a oneness with the notion; I stand with it and am entwined by it.

"When is it going to be on the road?" "When will it be ready?" "Haven't you got that thing finished yet?" "Oh, it's just autowrecker parts put together?!" "Is it a kit car?" "You paid how much?" "I could've done that cheaper." "You didn't need to do that." 
"You won't need that." "What's that old car you're fixin' up?" "Hot Rod?(!)" "Doesn't look like you've done anything." "Why don't you just buy one?" "Air conditioning!?"

These matter-of-fact statements do not show an appreciation of special. I perceive them negatively; they are slights on me personally; they force me to take refuge in the notion, to ask that it protect me. I hope that others will understand the notion one day.

Those who know special realize the journey is long and arduous, though diamonds of insight litter the path and brighten each step.

I'm sitting in my garage with the Model A. That afternoon we brought the body shell back from the body shop. The recessed firewall is finished, the roof has been filled with steel, the body seams which ran from the once-open roof to the rear deck have been removed. The new metal sun visor and visor underpanel have been installed. The new steel floorboards and crossmembers are in, as well as the new rear crossmember and body panel, and the few tiny lower quarter panel rust holes are gone. The body is perfect. That was the second major visit to the body shop for the shell; there will be many more.

"Wrought by fire." Did you hear the phrase? "Wrought by fire." What does it mean? Let me tell you. The normal process in creating objects of steel is that one considers the job against the available steel: materials which were wrought by fire from crushed rock having been blasted by fire from the ground. Once you have the steel, it is fire that will eventually nudge and cajole it into its place. But the entire task is not easy and the process, when considered in its totality from identified ore to functional integrated unit, is a singularly epic human endeavor that gives a metal worker a true connection with his humanness.

The normal process of building from steel has some additional aspects where special creativity is involved. The structure to be made must be designed thoughtfully with attention to both function and beauty. This is the essence of functional creativity. The sign of success is that the finished object be everything that the mind conceived.

The body shell was sitting on saw horses. The firewall at one time had been butchered by a primate with a cutting torch. The result was a gaping wound, rustily edged with weld-metal drips along the ragged hardened border. You see, one does not torch holes into steel, because it hardens and becomes unmanageable; forced, if you will. I had decided where to make my cut and this had been precisely scribed onto the face of the firewall. The cut was made softly and delicately with an electric jigsaw, feeling the grain of the steel as the loving cut proceeded. For a 50 -year-old body whose firewall had been abused at least a decade ago, this was the initial step toward a healing therapy. 
There were many times when I stood back, assessed and reassessed to the $n$th degree, trying to visualize the result. When the cut was finished it looked beautiful, exactly the shape I wanted, and the car was feeling good about it-I knew that. This process, then, eliminated all the old and unacceptable metal in order that I could graft on fresh new steel. It is like breaking the old counter productive habits for an athlete or musician. A decision is made at a critical fork in the road.

The next step was to purchase Bristol board from which to make patterns for the new structure and to order in a sheet of cold rolled (not hot-rolled!) mild steel of the correct thickness. In my mind I wanted the new firewall to look like "sculptured cut-chalk" - though I'm not certain that I was consciously aware of this vision until the job was finished. At this point I had certain functional realities to consider: realities such as clearance of the distributor cap and distributor for tune-ups, clearance of the transmission including the filler tube and linkages, orientation of the panel which was in future to support the lower steering column support and weatherseal, clearance for the power brake vacuum diaphragm, appropriately designed space for the brake metering valve and the carbureter linkage, and integration of the lower firewall with the new steel front floorboards. My design included seven separate steel sections, designed as Bristol board and taped together in place as a three-dimensional unit. Each pattern was transferred onto steel and jigsawed. As each piece took shape it was taped into place-now made of steel. Each of the panels over the transmission was carefully rolled to the correct curvature. Suddenly there it was, the once gaping wound filled; a completed stage, all pieces designed and in place. Now the welding. Hydrogen arc, or what one commonly refers to as arc-welding, will blow holes into this gauge of steel. Gas welding is out of the question because of distortion from general overheating, as the flame is not concentrated sufficiently. Another problem associated with arc welding comes from a special and deleterious crystallization effect called hydrogen embrittlement. The only choice is MIG welding (metallic inert gas, argon in this case). The benefits are numerous and include good heat penetration creating deep welds, no embrittlement, and welding capacity for body panel steel.

During the welding process you pray. Manual welding is not an exact science, as the steel wrought by fire is in a wild and rapid state of internal rearrangement. This is traumatic. That which was wrought by fire from the earth hit by blasting, crushed, then traumatized in the Bessemer converter, is now liquefied again. Altogether not an easy birth. Crafting is not ever easy, even for the materials involved.

This day prayers were not enough: Two miscalculations had caused one panel to distort. It would have to be shrunk and bodyworked. The other pieces survived their trial. I'll never forget seeing them all 
afterward though in machine-shop-become-recovery room.

The body shell went to the body shop where the shrinking was done. More steel was cut to fill the roof. (The Model A in stock configuration has a chicken wire and vinyl roof insert, but the strength is not there and the look is not smooth.) The roof panel was a single piece but not easy. The visor and visor underpanel and all the other new steel was installed-MIG welded. I went to the body shop every day (they understand me-they're craftspeople) to share the joy as design idea became fact. The fire wall was now exactly what I had pictured in my mind months before. It was a long moment of exhilaration. The body shell was a wonder. I couldn't thank them enough. Money is at this point merely a trade token to transfer work into goods. One must thank beyond money. These people appreciate my dream of special, for special too is a dream.

I transported the body home. I was elated. When I lowered it onto the chassis I had to get someone to share the moment but no one was around, so I played with our dog and we were there together-close and solitary: a canine and a primate connected somehow with our primeval ancestry.

\section{Showing}

Next day, Saturday, a friend-or sort of friend-came over and somehow the question came up, "How's the car?" Well, out to the garage we went. "Oh, you haven't done much?" "Well, actually, I've done quite a bit." I proceeded to show him. I just told him what had been done, certainly not how it was done. After the firewall, roof, and body seams, he said, "Great, when do you figure it'll be done?" My God! What?! I told him five years. He thought I was joking. I had to defend myself, my aims and my goals. He was just a spectator.

In order to construct the frame we ordered two-by-four inch box tubing of .177 inch wall thickness. I remember the first time I rested my eyes on it lying on the shop floor with its perfect blued machinewelded seams. The blueing from the weld penetration was remarkably deep and the curvature of the corners exquisitely precise. All those molecules sat there, silver and silver-blue, with that common destiny. I wondered where each particle had come from, and I wanted to tell each of them what they were to become a part of.

To most people a bare car frame is not capable of instilling awe and excitement. I really would not expect it to. Even a chassis replete with suspension and wheels does little. So as people saw the chassis there was no shared emotion.

Many rewards came to me during this period though, rewards from lovingly crafting a steel plate, or bending a conceptualized-designed-created piece to fit the Bristol board template and then the car. These were monastic rewards; no one to this day really knows how I could spend so much time in making each piece. In a way I was ensnared by special because the chassis was so good. (The fabricator 
was a craftsman and I often get advice from him.) I was gently trapped by special. I had known academically what special meant, but now it was starting to take me over and show me that it meant business. The notion controls and defines my actions and all the time rewards me with a sense of oneness with the notion.

Over the next few months the engine was built and installed. I was offered free engine-side motor mounts, but they were somewhat used and now I couldn't be unfaithful to the notion: I bought new ones. "No one does that," I was told. Well, I did it. The engine artpiece was installed. Now in my garage was a chassis, complete with running gear and body. We have a neighbor, Janice, whom I had gently forced to look at the frame and later at the chassis, then the engine, transmission and wheels. Later I showed her the body on its own.

She was over for a barbecue soon after the body was bolted to the completed chassis. We were sitting in the yard when to my astonishment my wife invited her to see my "car." What?! Suddenly it's a "car," and my wife is asking a girlfriend to see it? In placing the body on the chassis a total transformation had occurred: a transformation from car parts to car. The transformation was stunning. I had made a quantum leap. The journey is worth the effort; I was elevated by the notion that people's attitudes were changing by my example. "People do appreciate special." I remember the thought passing through my mind.

That night Heather and Janice went out. It was a summer night, light until about nine. I mocked the car up to locate where I should drill the body cross members to align with the frame. The mock-up included fenders, hood and grille, running boards, headlight crossbar, and headlights. As the daylight began to fade, I did too. I found a lawn chair and parked myself outside the garage door with the car peering out at me. As I looked in, it really hit home that the body, the shell, fenders, and grille were 55 years old. They were formed at the end of the roaring '20s, before the long years of the Great Depression, before the Second World War, television, atom bombs, and well before Viet Nam.

I knew the car had been dismantled at Cobble Hill on Vancouver Island, but that was all. I wondered what it had been through, and where. Perhaps I had seen it as a child; perhaps I had seen it in a documentary passing along the production line, being assembled by men in caps with rolled up sleeves and suspenders in black and white. The vast majority of these men are dead now. We learn the greatest thoughts of the ages from dead men; our freedoms were preserved by them. Dead men and women form a direct connection with the ages. This car is a concrete link to my ancestral past.

"Where has it been?" I wondered. "How did it get here?" If only it could tell me. I sat and thought; the car made me think. I was bringing it back to life. In that fading half light as I peered at its 
countenance, I saw in it something dark, serious, and ominous. I felt that this long lost character was somehow communicating with me, that it had seen serious business. I was somewhat frightened by it all. It was becoming more than just the sum of its parts. Where would all this lead? What had I wrought? The car had welded itself to me or perhaps I to it by way of communion. It was more than car, it was incarnate. Conceived by humans, designed and made by humans, now remade by humans, how could it be other than incarnate?

Heather knew nothing of this, but that week she named the car Mollie. She would not back off on this, neither would she accept an alternative name. The matter is out of my hands. Each of us thinks that naming a car is real kid-stuff, but communion is a two-way process.

\section{Paying}

Our next step was to connect the transmission to the rear end using a drive shaft. Having investigated while other things were being done, I had already procured the yoke which connects the drive shaft by a universal joint to the transmission. I had deburred it, smoothed it out, and painted it with gray lacquer for protection. I hoped that if I showed this to the drive shaft machinist he'd get an idea of the quality I demanded. He was poker-faced when I showed him the piece, but did show some emotion when I insisted on buying the shaft tubing itself from a "very expensive" supplier across town. "You could save money at the auto-wreckers," he suggested.

I replied, "I'm not interested in saving money." Well, when I picked up the tubing it was packed in a heavy cardboard tube. It was almost a religious event taking this out and cutting it. I took it out to my car and just marvelled at its perfect, polished concentric smoothness. "Wrought by fire." I got the other end of the drive shaft from the machinist, detailed it, and took all three pieces in for him to weld. All the pieces were wrapped in newly-laundered flannelette-the cleanest thing to enter his shop in years. He told me the welding would burn the paint off the yoke but I assured him that the paint was merely there to prevent rusting while other pieces were being collected. I don't think he understood. A few days later I went to pick the completed unit up; I love to see nice new welds. The welds were strong, yes they were, but they were ugly, and there was a pinhole in one weld. I asked him to fill the weld; he said it didn't matter! I asked him to turn the welds down to balance the drive shaft, to which he replied, "No one has that done." I paid. I paid basic money with no thanks for the job-and I left furious to return to the planet Mars. This man was simply not on the wavelength of special. $\mathrm{He}$ could not relate, his work was base, his shop was base. I let him fall by the wayside, a spectator. I felt toward him like oil and water, grease and ice perhaps. I took the shaft elsewhere to be finished. You 
tune into special people when you create something special. No wonder artists' communities spring up and thrive. They know the reward of demanding perfection.

I have in the course of construction managed to select books and magazines which I use for advice. In addition there are trade experts who sell me their services. In this sense though, "sell" is inaccurate. They keep me on track, they know the notion, and guide me in my journey, and have the courage to tell me when I falter.

I arrived at Boult and Son-trade experts-on a hot afternoon with a real problem over my transmission shifter. The one I wanted was outrageously overpriced and cheap ones were just that, cheap, and Kung-Fu-movie gaudy. I was shown that day how to build my own and was provided gratis with the only two special pieces I needed. It amazed me; I wondered just how much untapped special expertise there is around us-talent we just know nothing about. This has led me subsequently to building other working parts; you see, people who appreciate the notion of special will elevate you. Most of us know some of these people: they are embodiments of special.

The inner lining of a brake hose will often have a force of 10 to 15 tons trying to break outward. $\Lambda$ block of concretc 10 fect on each edge weighs about 15 tons. When you need special brake hoses you can't just go to a machine shop and have them made up. They're not just hoses, nor are they just ordinary hydraulic hoses. I had a supplier in Vancouver who could sell me the hoses needed at $\$ 50$ each-stainless braided racing hoses. I needed four of them. Boult and Son could get them no cheaper and following my lead with the beautiful shifter I had made, I asked if anyone in Penticton had a lead on where to have some made up, perhaps cheaper? Well, that went over like a lead balloon. "Don't risk it!" was the message I got. I knew that academically, but needed reminding. These people are not timid.

\section{The Acid Test}

Eventually when creating special things the acid test must be taken. It is a time of nervousness, of stomachs full of butterflies. This is true for the gymnast, actor, boatbuilder, house builder, coach, magician, or any craftsman. One must stand the test, the final scrutiny. In building cars it comes at two points. Firing up the engine and the first drive down the street.

I was nervous, deep down. There was a mild aroma of ether in the air mingled with other smells singular to an automotive shop floor. Seven years of hard work had led to this moment: the moment at which the balanced and highly machined internal engine parts would show us that we had created more power, more energy and living frenetic motion than we cared to contemplate, a Frankenstein of our own creation. 
Every component: connecting rods, bearings, pistons, piston rings, crankshaft, engine block, heads, valves, valve springs, retainers, push rods, camshaft, water pump, intake manifold, carbureter, distributor, exhaust headers, plug leads, plugs, pulleys, and fan belts had been individually selected to be part of the act. Each acceptable part was then machined to tolerance and set aside in oiled cloths until assembly. The engine block, LT 1 Corvette, was nearly a throw-away. I had searched for three months through perhaps 20 blocks and with each I had to talk to the dealership and check serial numbers to ensure success of the overboring operation should there be a taper or an out-of-round in a cylinder. New or "green" blocks are not used in these applications because they are unproven under stress conditions. The block was delivered to my house, dirty and used, but I had plans for it. I'd already found an engine machinist of some 25 years experience and I delivered the block to him.

That day at school I was tense as the block was being measured and scrutinized to determine if it was worth machining. I phoned and got the news. It was bad, but the machinist explained that there was hope. There was a bad taper in one cylinder. Twenty-four thousandths. The serial number of the block had told me the casting thickness of the cylinder walls and our maximum overbore was 60 thousandths diameter, 30 thousandths radius. If the taper went all one way we'd have to go to a maximum factory-recommended overbore. I didn't want to go that far; I didn't want to take the risk. At 10,000ths ("thou") the taper had not changed, at 20 it reduced, so we went to 30 . The taper was removed with a 40 thou overbore-the block had made it! I couldn't tell anyone though; how do you explain something like that? It was just the machinist and me, triumphant. Two days later in the afternoon I picked the block up with all the machining completed. It was ready for detailing-removal of all external and internal casting imperfections using a die grinder for some six hours. Then it was back to the machine shop for another caustic bath to remove all grinding metal, then home again for painting.

The gray-teal blue lacquer had arrived on special order and this job was quick after installing all the frost plugs. That engine started to breathe after painting and I'd always look at it differently from that point on because I knew it was special and was to be part of something special. I introduced it to the chassis, as I do with each part as it makes the grade.

Every piece was prepped like the block and many hours were spent with the crankshaft machinist (not the same as the block machinist) in educating him about my goals, as I got to know him while I worked on other chassis jobs. He eventually constructed the engine and it was used by his shop for advertising. There is a story to every single component of that car, a story of thought, design, trial, rethought, and retrial, all leading toward each individual part. Then the part 
would be either integrated, modified, or redesigned from scratch. It is hard to imagine, but there are over 4000 pieces on the average car and nothing designs and manufactures itself. Each piece is the result of design-application and thoughtfulness.

A chassis bolt, for instance, must be of the correct grade of hardness, toughness, and brittleness in order to survive, and to not survive at the expense of another component or fail incorrectly in a crash (failure sequences are planned for crash situations). None of this can be left to chance; too much is at risk-life and death in the case of failure. Chassis bushings must have machine tolerances and the material-Teflon in this case-must be right for a specific application. All chassis components must be adjustable for alignment, correct handling, and safety. Nothing can be left to chance. This trek is a challenge, constantly asking you if you have the right stuff. If you don't, you'll quit. Sometimes I've quit, I've quit for as long as four or five hours, but I'm always hooked back again.

Glen asked me to turn the key to accessory. The voltmeter and gas gauge flicked into life, ignition light on. No problem so far-my trial had begun. Daren't try the radio-we're here for business and we're serious.

"Turn it to 'On."”

"O.K." The gauges flick off and on. My eyes scan the others but glue themselves on the lifeline of the engine, the oil pressure gauge. If it doesn't read we're in really big trouble. If there is one critical gauge, one that we could do nothing without, it is that oil gauge. Images flash through my mind: the oil pump, the pump pickup, the safety wire holding the pickup to the pump, the pump bolts, the spring relief valve, and all the decisions taken and weighed on the pump type, its volume and relief pressure. There are special machine grooves in the pump to increase efficiency. These were all my decisions and now is the moment of truth.

The plug leads are not connected to the distributor so it won't fire yet.

"Crank it over."

"O.K. It's done. Nothing jammed." "Turn it off." "O.K. We'll do the distributor cap." Snap! Snap! Snap! Snap! Snap! Snap! Snap! Snap! "They're all on." "Fire it up, let me control the gas," says Glen. I crank, the engine sounds tight (doesn't sound right I don't think). I, VAROOM-IT'S ALIVE! Oil pressure 60 pounds, the tachometer needle moves so beautifully, so fluidly. The ether smells so sweet. I don't know what to do. I holler. My nightmares haven't come true. How long has it been since a heart beat in the breast of this car? How long since the warm vibration of motion passed through the steel. Old and new steel united in one living unit. It's a harmony we've reached. Man, the doer of things-creator, assembler, and orchestrater. 
I step out of the car and stand by the engine, my face soaking in the heat. I can feel the movement right up through my feet. The delicate pinging in the black header pipes is music to my senses and still the delicate aroma of ether permeates the air. The ether now is even more aromatic as the waves of heat have brought it to life. Fan belts swirl in trained frenzy, pulleys reflect fluorescent light and above it all the carburetor draws a steady flowing and measured hiss of air. Peering in the carburetor I see a perfect steady shaped cone of atomized gas hurtling downward. The waves of heat wrap my face. The aroma of hot new paint mixes into the symphony. Placing palm to rocker covers I feel the movement of valve train frenetic and disciplined.

I circle to the rear, to the tail pipes. They're so quiet but underneath I can hear every explosion of the rapid muffled symphony. I am enveloped by the celebration. The pipes are starting to become warm, and it's warmth that is there because of my perseverence. I'm exhilarated, vindicated, fulfilled. It was all worth it. It is special.

I could just buy a car. But then I would never have understood the notion of special in crafting. 